\title{
Sedation for Pediatric Endoscopy
}

\author{
Myung Chul Lee \\ Department of Pediatrics, Maryknoll Medical Center, Busan, Korea
}

\begin{abstract}
It is more difficult to achieve cooperation when conducting endoscopy in pediatric patients than adults. As a result, the sedation for a comfortable procedure is more important in pediatric patients. The sedation, however, often involves risks and side effects, and their prediction and prevention should be sought in advance. Physicians should familiarize themselves to the relevant guidelines in order to make appropriate decisions and actions regarding the preparation of the sedation, patient monitoring during endoscopy, patient recovery, and hospital discharge. Furthermore, they have to understand the characteristics of the pediatric patients and different types of endoscopy. The purpose of this article is to discuss the details of sedation in pediatric endoscopy.
\end{abstract}

Key Words: Sedation, Endoscopy, Pediatric

\section{INTRODUCTION}

Pediatric patients are less cooperative than adult patients when they undergo endoscopy, and their parents also experience more anxiety with regard to the procedure. Furthermore, the satisfaction of the patients and their parents has recently emphasized. Even though the sedation in pediatric patients is one of the most important factors of endoscopy, there are not many hospitals that use standardized guidelines such as those published by the American Academy of Pediatrics (AAP) and American Society of Anesthesiologists (ASA). This article discusses the details of sedation for pediatric endoscopy, including the purposes of sedation, levels of sedation, medical history of the patients, physical examination, preparation before the procedure, selection of medication, patient monitoring, patient recovery, and discharge decision based on the above-mentioned guidelines.

\section{PURPOSES OF SEDATION}

The following purposes of sedation are addressed by the AAP [1]. (1) Guarantee the patient's safety and welfare; (2) reduce physical pain; (3) minimize anxiety and maximize the potential for amnesia; (4) control patient's movement for the safe procedure; (5) discharge the patient safely. The level of sedation, monitoring, type of sedative agents, and their dosage are determined based on the patient's status, age, purpose, type of procedure, and opinion of the patient or their caregivers/parents.

Received : February 19, 2014, Revised : March 12, 2014, Accepted : March 17, 2014

Corresponding author: Myung Chul Lee, Department of Pediatrics, Maryknoll Medical Center, 121, Junggu-ro, Jung-gu, Busan 600-730, Korea. Tel: +82-51-461-2303, Fax: +82-51-465-7470, E-mail: id2072@naver.com 


\section{LEVELS OF SEDATION}

There have been various terminologies to describe the levels of sedation. The AAP and ASA classify it into four categories which are minimal sedation, moderate sedation, deep sedation, and general anesthesia $[1,2]$. During minimal sedation, cognitive function and coordination may be impaired, and patients respond normally to verbal commands. During moderate sedation, patients respond purposefully to verbal commands whereas their consciousness is depressed. During deep sedation, patients have also depressed level of consciousness whereas they respond purposefully to repeated or painful stimulation. During general anesthesia, patients are not arousable, even by painful stimulation. Ventilatory and cardiovascular functions are usually maintained during minimal or moderate sedation. But ventilatory function may be impaired during deep sedation, and often impaired during general anesthesia. During general anesthesia, cardiovascular function may be impaired.

\section{CHARACTERISTICS OF ENDOSCOPY}

In esophagogastroduodenoscopy (EGD), gagging and poor cooperation can be problem. The use of a local spray or oral medication before the insertion of the intravenous line prevents gagging and increases the cooperation of patients for EGD, which leads to the improvement of tolerance and satisfaction in pediatric patients $[3,4]$. In colonoscopy, the visceral pain associated with looping should be avoided.

Table 1. American Society of Anesthesiologists (ASA) Classification of Patient's Physical Status

\begin{tabular}{cl}
\hline ASA class & \multicolumn{1}{c}{ Physical status } \\
\hline 1 & Normal healthy patient \\
2 & Patient with mild systemic disease \\
3 & Patient with severe systemic disease \\
4 & Patient with severe systemic disease that is \\
& a constant threat to life \\
5 & Moribund patient not expected to survive without \\
& emergent procedure \\
\hline
\end{tabular}

Adapted from the article of American Academy of Pediatrics et al. (Pediatrics 2006;118:2587-602) [1].

\section{AGE OF THE PATIENTS}

The effect of sedation appears differently depending on the age of the pediatric patients $[5,6]$. Infants who are younger than 6 months of age may have little anxiety and may be easily affected by the sedation. However, patients, who are 6 months of age or older, have already developed stranger anxiety and they may require their parents to remain next to them during the induction. For school-age children, it is surprisingly difficult to sedate them as they have developed concrete thinking. As a result, it is recommended to carefully discuss what to expect during the procedure in order to decrease their anxiety level. Adolescents may be cooperative before the procedure, but they may also exhibit disinhibition and strong anxiety with initial doses of sedatives.

\section{ASSESSMENT OF THE RISK FACTORS AND AIRWAY}

A thorough assessment of the patient's physical condition should be conducted regarding the suitability for sedation before the endoscopy. Physicians are recommended to use the ASA classification of the patient's physical status in order to determine the appropriate level of sedation (Table 1) [1,7]. For example, patients without underlying disease fall under the ASA class 1, while those with controlled asthma fall under the ASA class 2. The asthma patients with clear signs of wheezing fall under the ASA class 3, and those with status asthmaticus fall under the ASA class 4. The patients who have severe myocardiopathy and are candidates for heart transplant are classified into the ASA class 5.

Table 2. Modified Mallampati Score for Airway Assessment

\begin{tabular}{cl}
\hline Class & \multicolumn{1}{c}{ Physical status } \\
\hline I & Uvula is completely visible \\
II & Partially visible uvula \\
III & Soft palate visible but not uvula \\
IV & Hard palate visible only, not soft or uvula \\
\hline
\end{tabular}

Adapted from the article of Samsoon and Young (Anaesthesia 1987;42:487-90) [8]. 
Moreover, the airway of the patients should be assessed before the endoscopy. The use of a grading system, such as the modified Mallampati score, is helpful in the assessment of risk factors pertaining to airway difficulty (Table 2) [8].

\section{DIET PRECAUTIONS}

The pediatric patients, who are candidates for elective endoscopy, should follow the preoperative fasting guideline before undergoing general anesthesia (Table
3) [2]. A routine and necessary medication is allowed to be taken with a little amount of water. For emergent endoscopy, the risk of non-fasting and necessity of the procedure should be considered altogether.

\section{SEDATIVE AGENTS FOR CHILDREN UNDERGOING ENDOSCOPY}

The medications that are commonly used for the sedation of pediatric patients are summarized in Table $4[6,9,10]$.

Table 3. Appropriate Intake of Food and Liquids before Elective Sedation

\begin{tabular}{llc}
\hline & Ingested material & $\begin{array}{c}\text { Minimum } \\
\text { fasting period (h) }\end{array}$ \\
\hline Clear liquids & Water, fruit juiceswithout pulp, carbonated beverages, clear tea, black coffee & 2 \\
$\begin{array}{l}\text { Breast milk } \\
\text { Infant formula }\end{array}$ & & 4 \\
Nonhuman milk & Since nonhuman milk is similar to solids in gastric emptying time, the amount & 6 \\
& ingested must be considered when determining an appropriate fasting period & 6 \\
Light meal & A light meal typically consists of toast and clear liquids. Meals that include fried & 6 \\
& or fatty foods or meat may prolong gastric emptying time; both the amount and \\
& type of foods ingested must be considered when determining an appropriate \\
& fasting period & \\
\hline
\end{tabular}

Adapted from the article of American Society of Anesthesiologists Task Force on Sedation and Analgesia by Non-Anesthesiologists. Anesthesiology 2002;96:1004-17 [2].

Table 4. Recommendations for Dosages of Drugs Commonly Used for Intravenous Sedation for Pediatric Gastrointestinal Procedures

\begin{tabular}{|c|c|c|c|}
\hline Sedatives & Usual dosage & $\begin{array}{c}\text { Time to } \\
\text { onset (min) }\end{array}$ & $\begin{array}{l}\text { Duration of } \\
\text { action (min) }\end{array}$ \\
\hline \multicolumn{4}{|l|}{ Sedative agents } \\
\hline Midazolam & & $2-3$ & $45-60$ \\
\hline Infants 6 months-children 5 years & $0.05-0.1 \mathrm{mg} / \mathrm{kg}$ & & \\
\hline Children 6-12 years & $0.025-0.05 \mathrm{mg} / \mathrm{kg}$ & & \\
\hline Children 12 years-adults & $1-2.5 \mathrm{mg} / \mathrm{kg}$ & & \\
\hline Meperidine & $1-3 \mathrm{mg} / \mathrm{kg}$ & $<5$ & $120-240$ \\
\hline Fentanyl & & $2-3$ & $30-60$ \\
\hline Neonates and younger infants & $\mathrm{l}-4 \mu \mathrm{g} / \mathrm{kg}$ & & \\
\hline Older infants and Children 1-12 years & $1-2 \mu \mathrm{g} / \mathrm{kg}$ & & \\
\hline Children $>12$ years and adults & $0.5-1 \quad \mu \mathrm{g} / \mathrm{kg}$ & & \\
\hline Ketamine & $0.5-2 \mathrm{mg} / \mathrm{kg}$ & 1 & $15-60$ \\
\hline Propofol & $1.5-3 \mathrm{mg} / \mathrm{kg}$ & 0.5 & $3-10$ \\
\hline \multicolumn{4}{|l|}{ Reversal agents } \\
\hline Flumazenil & $0.01 \mathrm{mg} / \mathrm{kg}$ & $1-2$ & $<60$ \\
\hline Naloxone & $0.1 \mathrm{mg} / \mathrm{kg}$ & $2-5$ & $20-60$ \\
\hline
\end{tabular}

Modified from the article of Lightdale. Tech Gastrointest Endosc 2013;15:3-8 [6].

Modified from Nelson textbook of pediatrics. 18th ed. Philadelphia: Saunders Elsevier, 2007:2955-99 [9].

Modified from Pediatric dosage handbook. 1lth ed. Hudson, Ohio: Lexi-Comp Inc., 2004:997-1000 [10]. 


\section{Midazolam}

Midazolam belongs to benzodiazepines with an onset of action of 2-3 minutes, and peak effect achieved at approximately 45 minutes up to 1 hour. Benzodiazepines are expected to cause anxiolysis and amnesia. However, these bring about paradoxical reactions in pediatric patients, thereby making them more anxious and agitated [11]. The dose of midazolam per body weight is often higher in the pediatric patients than the adult patients due to their fast metabolism and excretion $[4,12,13]$. Furthermore, the clearance of the medication increases with the dosage [14]. The side effect of midazolam, which is a major cause for concern, is respiratory depression that is known to be dose-dependent. When midazolam is used with opioid $[15,16]$ or used in patients with enlarged tonsil $[1,17,18]$, the risk of respiratory depression is increased.

\section{Meperidine}

Meperidine belongs to opioids and it is mainly known to control pain. Its action duration is approximately 2-4 hours, which is considerably long [6]. Its side effect involves the development of respiratory depression, while normeperidine, the metabolite of meperidine, may cause seizure. In particular, the seizure appears when the reversal agent is used to help the patient breathe, thereby allowing the possibility of a serious medical situation. Meperidine should not be used in patients who are taking monoamine oxidase inhibitors. Patients who are taking phenytoin have the possibility of a decrease in effect of meperidine. As a result, meperidine is not recommended for pediatric patients due to the above-mentioned side effects and prolonged duration.

\section{Fentanyl}

Fentanyl also belongs to opioids, and the onset of its effect is within 30 seconds. The peak effect comes within 2-3 minutes from the time of administration, and it lasts for approximately 30-60 minutes [6]. It is often used with other drugs, including midazolam, because fentanyl does not have an amnesic effect. There are rare instances of chest wall rigidity when a high dose is quickly administered; therefore, a slow push is recommended [19]. Severe apnea has often been reported in patients under 3 months old [20]. The delayed respiratory depression often causes problems. These problems occur in infants with blood circulation problems in the liver and decreased excretion [21]. These are also associated with the termination of its effect by redistribution of metabolites in the plasma rather than its metabolism. For safety reasons, it is recommended to administer the drug a few minutes apart between each dose in small increments.

\section{Ketamine}

Ketamine is a dissociative agent, which has an excellent analgesic effect. It also induces a trancelike cataleptic condition. Its side effects include laryngospasm, airway obstruction, and excessive secretion of saliva. Some patients experience hallucination during the recovery. In order to prevent this, benzodiazepines, such as midazolam, are sometimes used beforehand [22]. Ketamine must not be used in patients who are under 3 months old, or who have unstable airway, cardiovascular disease, central nervous system disease, psychosis, porphyria, or thyroid disease [23].

\section{Propofol}

Propofol has a very short time of onset and action duration. It also has excellent antiemetic and amnesic effects, but without an analgesic effect. The therapeutic range of propofol is narrow and the dose per body weight is different from the age of patients. Therefore, there is a high possibility for the induction of general anesthesia to the patients due to a dosage inaccuracy $[24,25]$. It may cause pain in the injection site, respiratory depression, and excessive secretion. A few cases of continuous infusion of propofol for more than 5 hours have caused a severe side effect called propofol infusion syndrome; however, it was out of consideration for a short procedure such as endoscopy.

\section{Practice of sedative agents}

Commonly used drugs are benzodiazepines and 
opioids. Midazolam alone provides amnesia and anxiolysis effect. Benzodiazepine/opioid combination gives analgesic effect, increase amnesia and sedation, and increase patient satisfaction [26]. Availability of specific antagonists for these agents is the attractive point when using these medications. For these reasons, midazolam alone or midazolam/opioid combination is strongly preferred by gastroenterologists [27-30]. However, benzodiazepine/opioid combination has relatively long time to achieve adequate sedation, procedure, and recovery [31]. In addition, restraint is often needed [31].

Propofol has narrow therapeutic range. Because of this disadvantage, propofol occasionally induces deep sedation or general anesthesia, while specific antagonist is not available. Therefore, the administration of propofol had been restricted primarily to anesthesiologists and trained nurse anesthetists in order to manage airway in emergency. However, propofol has been noticed on account of the rapid time to onset and recovery time, in addition to the better or similar patient satisfaction [32,33]. Some recent studies suggest that propofol can be safely administered to children by nonanesthesiologists who specifically trained to follow established safety guideline [31]. Nevertheless, propofol is still a cautious agent for children.

\section{PATIENT MONITORING DURING ENDOSCOPY}

In the past, cyanosis was observed with naked eyes to monitor the patient's breathing. Recently, the pulse oximetry has become a widely used device, and it has contributed greatly to the reduction of endoscopy complication rate. The pulse oximetry, however, has limitations. It shows lots of artifact, which prompts the staff to frequently check both the pulse oximetry and the patients. Furthermore, because oximetry presents oxygenation, not ventilation, it takes a longer time to become desaturated after the ventilation has been stopped [34]. As a result, a capnography device is recommended in order to detect the end-expiratory carbon dioxide level. The level of carbon dioxide from the mouth and nose is collected through the catheter of the capnography device and it is converted into a real-time graph. Using capnography in the pediatric endoscopy setting may reveal the occurrence of abnormal ventilation with unexpected higher rates during the procedures done on children [35].

In order to monitor the cardiovascular system of the patients, blood pressure measurement and electrocardiography can be used. Blood pressure measurement is recommended every 5 minutes after the initial measurement at the beginning of the procedure, while electrocardiography is recommended to be used for all deep sedation or moderate sedation in patients with significant cardiovascular diseases [2].

\section{DISCHARGE CRITERIA}

The patients should stay in the recovery room of the hospital equipped with oxygen administration, airway management, appropriate monitoring, and emergency treatment until they are suitable for discharge. Physicians can use the ASA guideline [2]

Table 5. Guideline for Discharge after Sedation

1. Patients should be alert and oriented; infants and patients whose mental status was initially abnormal should have returned to their baseline status. Practitioners and parents must be aware that pediatric patients are at risk for airway obstruction should the head fall forward while the child is secured in a car seat.

2. Vital signs should be stable and within acceptable limits.

3. Use of scoring systems may assist in documentation of fitness for discharge.

4. Sufficient time (up to $2 \mathrm{~h}$ ) should have elapsed after the last administration of reversal agents (naloxone, flumazenil) to ensure that patients do not become resedated after reversal effects have worn off.

5. Outpatients should be discharged in the presence of a responsible adult who will accompany them home and be able to report any postprocedure complications.

6. Outpatients and their escorts should be provided with written instructions regarding postprocedure diet, medications, activities, and a phone number to be called in case of emergency.

Adapted from the article of American Society of Anesthesiologists Task Force on Sedation and Analgesia by Non-Anesthesiologists. Anesthesiology 2002;96:1004-17 [2]. 
Table 6. The Modified Aldrete Scoring System

\begin{tabular}{lc}
\hline \multicolumn{1}{c}{ Time } & Score \\
\hline Activity & \\
Able to move 4 extremities voluntarily or on command & 2 \\
Able to move 2 extremities voluntarily or on command & 1 \\
Unable to move extremities voluntarily or on command & 0 \\
Respiration & 2 \\
Able to breathe deeply and cough freely & 1 \\
Dyspnea or limited breathing & 0 \\
Apneic & \\
Circulation & 2 \\
Blood pressure $\pm 20 \%$ of pre-anesthetic level & 1 \\
Blood pressure $\pm 20 \%$ to $49 \%$ of pre-anesthetic level & 0 \\
Blood pressure $\pm 50 \%$ of pre-anesthetic level & \\
Consciousness & 2 \\
Fully awake & 1 \\
Arousable on calling & 0 \\
Not responding & \\
$\mathrm{O}_{2}$ Saturation & \\
Able to maintain $\mathrm{O}_{2}$ saturations $>92 \%$ on room air & 2 \\
Needs $\mathrm{O}_{2}$ inhalation to maintain $\mathrm{O}_{2}$ saturations $>90 \%$ & 1 \\
$\mathrm{O}_{2}$ saturation $<90 \%$ even with $\mathrm{O}_{2}$ supplementation & 0 \\
Total score & 10 \\
\hline
\end{tabular}

Adapted from the article of Aldrete. J Clin Anesth 1995;7:89-91 [36].

(Table 5) or scaling system, such as the Modified Aldrete score (Table 6) [36]. The modified Aldrete score of at least 9 out of 10 means patient readiness for discharge [37].

\section{CONCLUSION}

Sedation during endoscopy is now considered to be more important; however, successful sedation is hard to achieve in pediatric patients. For a successful and safe sedation, physicians and all staff members should be sufficiently trained and educated, following the standardized guideline from preparation of sedation to discharge.

\section{REFERENCES}

1. American Academy of Pediatrics; American Academy of Pediatric Dentistry, Coté CJ, Wilson S; Work Group on Sedation. Guidelines for monitoring and management of pediatric patients during and after sedation for diagnostic and therapeutic procedures: an update. Pediatrics 2006;118:2587-602.
2. American Society of Anesthesiologists Task Force on Sedation and Analgesia by Non-Anesthesiologists. Practice guidelines for sedation and analgesia by non-anesthesiologists. Anesthesiology 2002;96:1004-17.

3. Fox V. Upper gastrointestinal endoscopy. In: Walker WA, Durie PR, Hamilton JR, Walker-Smith JA, Watkins JB, eds. Pediatric gastrointestinal disease: pathophysiology, diagnosis, management. St. Louis: Mosby, 2000:1514-32.

4. Liacouras CA, Mascarenhas M, Poon C, Wenner WJ. Placebo-controlled trial assessing the use of oral midazolam as a premedication to conscious sedation for pediatric endoscopy. Gastrointest Endosc 1998;47: 455-60.

5. Squires RH Jr, Morriss F, Schluterman S, Drews B, Galyen L, Brown KO. Efficacy, safety, and cost of intravenous sedation versus general anesthesia in children undergoing endoscopic procedures. Gastrointest Endosc 1995;41:99-104.

6. Lightdale JR. Sedation for pediatric endoscopy. Tech Gastrointest Endosc 2013;15:3-8.

7. Sidi A, Lobato EB, Cohen JA. The American Society of Anesthesiologists' Physical Status: category V revisited. J Clin Anesth 2000;12:328-34.

8. Samsoon GL, Young JR. Difficult tracheal intubation: a retrospective study. Anaesthesia 1987;42:487-90.

9. Peter G, Michael DR. Medications. In: Kliegmen RM, Behrman RE, Jenson HB, Stanton BF, eds. Nelson textbook of pediatrics. 18th ed. Philadelphia: Saunders Elsevier, 2007:2955-99.

10. Taketomo CK, Hodding JH, Karus DM. Pediatric dosage handbook: including neonatal dosing, drug administration \& extemporaneous preparations, 2004-2005. 11th ed. Hudson, Ohio: Lexi-Comp Inc., 2004:997-1000.

11. Massanari M, Novitsky J, Reinstein LJ. Paradoxical reactions in children associated with midazolam use during endoscopy. Clin Pediatr (Phila) 1997;36:681-4.

12. Tolia V, Brennan S, Aravind MK, Kauffman RE. Pharmacokinetic and pharmacodynamic study of midazolam in children during esophagogastroduodenoscopy. J Pediatr 1991;119:467-71.

13. Salonen M, Kanto J, Iisalo E, Himberg JJ. Midazolam as an induction agent in children: a pharmacokinetic and clinical study. Anesth Analg 1987;66:625-8.

14. Jacobsen J, Flachs H, Dich-Nielsen JO, Rosen J, Larsen $\mathrm{AB}$, Hvidberg EF. Comparative plasma concentration profiles after i.v., i.m. and rectal administration of pethidine in children. Br J Anaesth 1988;60:623-6.

15. Yaster M, Nichols DG, Deshpande JK, Wetzel RC. Midazolam-fentanyl intravenous sedation in children: case report of respiratory arrest. Pediatrics 1990;86: 
463-7.

16. Krauss B, Green SM. Sedation and analgesia for procedures in children. N Engl J Med 2000;342:938-45.

17. Coté CJ, Karl HW, Notterman DA, Weinberg JA, McCloskey C. Adverse sedation events in pediatrics: analysis of medications used for sedation. Pediatrics 2000;106:633-44.

18. Malviya S, Voepel-Lewis T, Tait AR. Adverse events and risk factors associated with the sedation of children by nonanesthesiologists. Anesth Analg 1997;85: 1207-13.

19. Arandia HY, Patil VU. Glottic closure following large doses of fentanyl. Anesthesiology 1987;66:574-5.

20. Balsells F, Wyllie R, Kay M, Steffen R. Use of conscious sedation for lower and upper gastrointestinal endoscopic examinations in children, adolescents, and young adults: a twelve-year review. Gastrointest Endosc 1997;45:375-80.

21. Koehntop DE, Rodman JH, Brundage DM, Hegland MG, Buckley JJ. Pharmacokinetics of fentanyl in neonates. Anesth Analg 1986;65:227-32.

22. Motamed F, Aminpour Y, Hashemian H, Soltani AE, Najafi M, Farahmand F. Midazolam-ketamine combination for moderate sedation in upper GI endoscopy. J Pediatr Gastroenterol Nutr 2012;54:422-6.

23. Green SM, Nakamura R, Johnson NE. Ketamine sedation for pediatric procedures: Part 1, A prospective series. Ann Emerg Med 1990;19:1024-32.

24. Schüttler J, Ihmsen H. Population pharmacokinetics of propofol: a multicenter study. Anesthesiology 2000;92: 727-38.

25. Eyres R. Update on TIVA. Paediatr Anaesth 2004;14: 374-9.

26. Standards of Practice Committee of the American Society for Gastrointestinal Endoscopy, Lichtenstein DR, Jagannath S, Baron TH, Anderson MA, Banerjee $\mathrm{S}$, et al. Sedation and anesthesia in GI endoscopy. Gastrointest Endosc 2008;68:815-26.

27. Benson AA, Cohen LB, Waye JD, Akhavan A, Aisenberg J. Endoscopic sedation in developing and developed countries. Gut Liver 2008;2:105-12.

28. Cohen LB, Wecsler JS, Gaetano JN, Benson AA, Miller $\mathrm{KM}$, Durkalski V, et al. Endoscopic sedation in the United States: results from a nationwide survey. Am J Gastroenterol 2006;101:967-74.

29. Chen $\mathrm{PH}, \mathrm{Wu}$ TC, Chiu CY. Pediatric gastrointestinal endoscopic sedation: a 2010 nationwide survey in Taiwan. Pediatr Neonatol 2012;53:188-92.

30. Ryoo E, Kim KM; Scientific Committee of the Korean Society of Pediatric Gastroenterology, Hepatology, and Nutrition. Pediatric endoscopic sedation in korea: a survey of the Korean society of pediatric gastroenterology, hepatology and nutrition. Korean J Pediatr Gastroenterol Nutr 2008;11:21-7.

31. van Beek EJ, Leroy PL. Safe and effective procedural sedation for gastrointestinal endoscopy in children. $\mathrm{J}$ Pediatr Gastroenterol Nutr 2012;54:171-85.

32. Lightdale JR, Valim C, Newburg AR, Mahoney LB, Zgleszewski S, Fox VL. Efficiency of propofol versus midazolam and fentanyl sedation at a pediatric teaching hospital: a prospective study. Gastrointest Endosc 2008;67:1067-75.

33. Abu-Shahwan I, Mack D. Propofol and remifentanil for deep sedation in children undergoing gastrointestinal endoscopy. Paediatr Anaesth 2007;17:460-3.

34. Vargo JJ, Zuccaro G Jr, Dumot JA, Conwell DL, Morrow JB, Shay SS. Automated graphic assessment of respiratory activity is superior to pulse oximetry and visual assessment for the detection of early respiratory depression during therapeutic upper endoscopy. Gastrointest Endosc 2002;55:826-31.

35. Lightdale JR, Sethna NF, Heard LA, Donovan KM, Fox VL. A pilot study of end-tidal carbon dioxide monitoring using microstream capnography in children undergoing endoscopy with conscious sedation. Gastrointest Endosc 2002;55:AB144-6.

36. Aldrete JA. The post-anesthesia recovery score revisited. J Clin Anesth 1995;7:89-91.

37. Miller RD. Miller's anesthesia. 6th ed. Philadelphia: Saunders Elsevier, 2005:2708-9. 